\title{
Endoscope-assisted contralateral transmaxillary approach to the clivus and the hypoglossal canal: technical case report
}

\author{
*Eva Pamias-Portalatin, MD, ${ }^{1,3}$ Deependra Mahato, DO, ${ }^{3}$ Jordina Rincon-Torroella, MD, ${ }^{2}$ \\ Tito Vivas-Buitrago, MD, ${ }^{3,4}$ Alfredo Quiñones-Hinojosa, MD, ${ }^{3}$ and Kofi O. Boahene, MD ${ }^{2}$
}

${ }^{1}$ Department of Neurosurgery, University of Puerto Rico Medical Science Campus, San Juan, Puerto Rico; ${ }^{2}$ Department of
Neurosurgery, Johns Hopkins University School of Medicine, Baltimore, Maryland; ${ }^{3}$ Department of Neurosurgery, Mayo Clinic
School of Medicine, Jacksonville, Florida; and ${ }^{4}$ Universidad de Santander UDES, School of Medicine, Bucaramanga, Colombia

Clival lesions are still considered surgically complex due to their anatomical location. Critical structures, such as the internal carotid arteries (ICAs), cavernous sinuses, cranial nerves, and brainstem, may be encased within the lesion. Although advances in endoscopic endonasal approaches have provided new routes to these lesions, exposure and resection of clival tumors through the endonasal route remain a technical challenge. Here, the authors report a left-sided endoscopic transmaxillary approach to access the right aspect of the clivus and the hypoglossal canal.

A 35-year-old woman presented with progressive right 6th cranial nerve palsy. MRI revealed a contrast-enhancing right petroclival chondrosarcoma that involved Meckel's cave and extended into the right hypoglossal canal. An endoscopiccontralateral-transmaxillary approach through a left sublabial incision was used to access the right petroclival region and right hypoglossal canal. A left maxillary osteoplastic flap was elevated to expose the left maxillary sinus. This was followed by a left medial maxillectomy, gaining access to the left posterior nasal cavity. The posterior third of the left inferior turbinate and nasal septum were removed to access the right side of the petroclival region. Near-total resection was achieved without any vascular or neurological complications. A thin shell of residual tumor was left behind due to involvement of vital structures, such as the ICA, and further treated with proton-beam radiotherapy.

The endoscopic-contralateral-transmaxillary approach provides a direct surgical corridor and good lateral visualization of the skull base vasculature. This approach allows wide maneuverability around the ICA and hypoglossal canal, which, in this case, allowed maximal tumor resection with full preservation of neurological function.

https://thejns.org/doi/abs/10.3171/2018.1.JNS171972

KEYWORDS endoscope; contralateral; transmaxillary; tumor; clivus; hypoglossal canal; skull base; chondroscarcoma; pituitary surgery

$\mathrm{C}$ LIVAL tumors are extremely rare. They represent only $0.1 \%$ to $0.2 \%$ of all intracranial tumors, with chordoma and chondrosarcoma being the most common pathologies. ${ }^{33,38}$ Nonetheless, tumor that involves the clival region is still considered one of the most challenging skull base cases. The clivus is located at the center of the skull base. Surgical access to the clivus is limited by its deep location and the intersection of vital vascular structures and cranial nerves. Chondrosarcomas are gen- erally low-grade, indolent lesions, but they can cause significant morbidity by invading and compressing surrounding neurovascular structures. Clival chondrosarcomas are rare tumors that are thought to originate from primitive mesenchymal cells. These primitive mesenchymal cells are located in regions of endochondral calcification of the skull base, such as the petroclival fissure. ${ }^{27,33,38}$ Therefore, only $1 \%$ of chondrosarcomas occur in the skull base, of which $66 \%$ arise from the petroclival fissure. ${ }^{7,84}$ The

ABBREVIATIONS $C N=$ cranial nerve; $I C A=$ internal carotid artery.

SUBMITTED August 14, 2017. ACCEPTED January 15, 2018.

INCLUDE WHEN CITING Published online June 22, 2018; DOI: 10.3171/2018.1.JNS171972.

${ }^{*}$ E.P.P. and D.M. contributed equally to this work. 


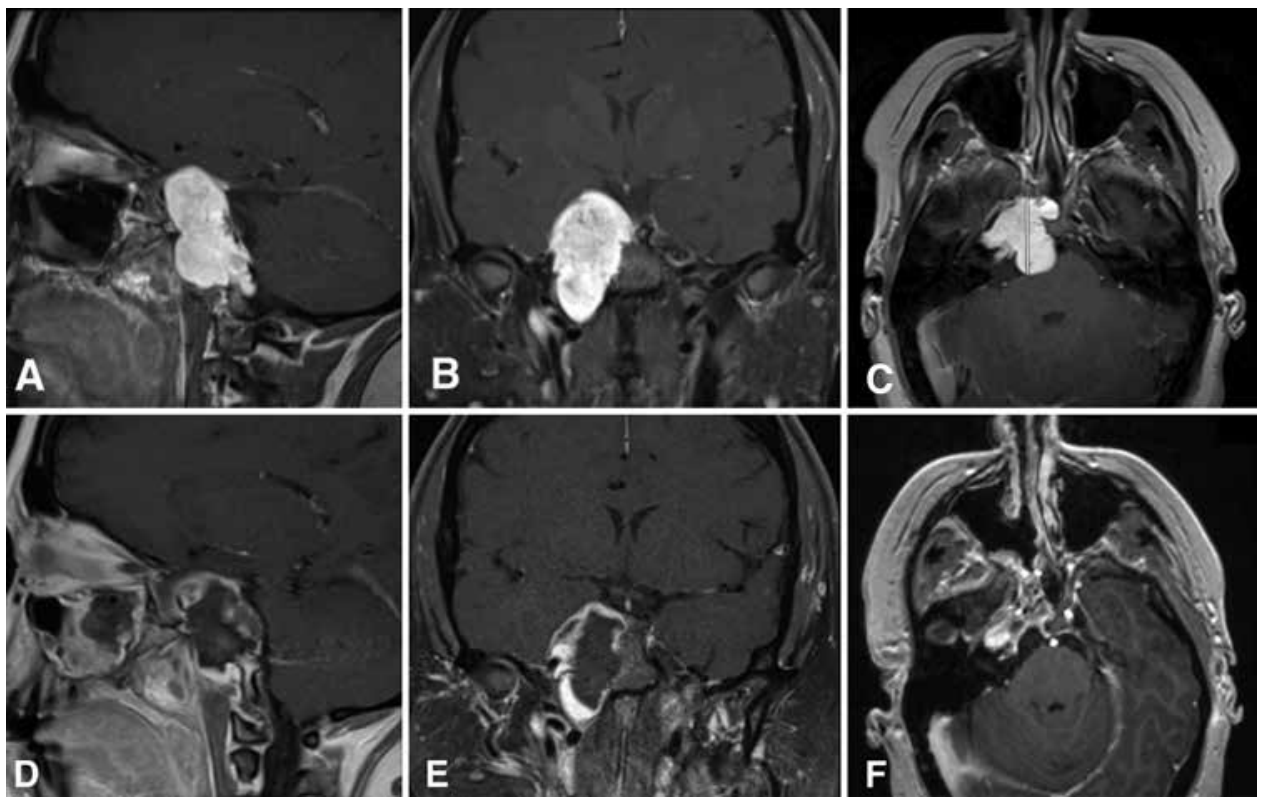

FIG. 1. Preoperative sagittal (A), coronal (B), and axial (C) T1-weighted images with gadolinium showing a contrast-enhancing lesion at the right petroclival region posterior to the right ICA, consistent with chondrosarcoma. Postoperative sagittal (D), coronal $(\mathbf{E})$, and axial (F) T1-weighted images with gadolinium showing a postresection cavity with optimal decompression.

management of chondrosarcomas is mainly surgical, and the patient's outcome is very dependent on the extent of resection. ${ }^{42}$ Given that the tumor's primary extradural location is at the skull base, the most common routes of access are the endonasal, transoral, and midline palatal split approaches. ${ }^{911,28,29,40}$ A small percentage of clival chondrosarcomas can grow intradurally, and those are usually resected through frontotemporal, subtemporal, transtentorial, transpetrosal, presigmoid, and retrosigmoid approaches. ${ }^{3,10,17,21,22,26,34,36}$ However, these approaches provide limited exposure to the clivus, and drilling in this area can be both difficult and hazardous. ${ }^{2,18,28,30,35}$ The transmaxillary approach has been shown to provide a good exposure to the lateral, upper, and middle clivus as well as the hypoglossal canal, with lower rates of complications. ${ }^{4,40}$ With the introduction of endoscopic techniques to brain surgery and the advances in the expanded endoscopic endonasal approaches, the transnasal route provides an optimal visualization of tumors located in the midline ${ }^{6,31}$ However, one major limitation of the endonasal route is the limited visualization and access to tumors located at the lateral aspect of the clivus. ${ }^{20-22}$ In this article, we report a difficult case of a right petroclival chondrosarcoma with involvement of the hypoglossal canal removed through a contralateral approach via a left-sided sublabial endoscopic transmaxillary technique.

\section{Case Report}

This 35-year-old woman presented with a 1-year history of progressive headaches, diplopia, and right facial pain refractory to medical management. On physical examination, the patient was noted to have a right cranial nerve (CN) VI palsy with right eye intorsion on attempted abduction. Results of the rest of her neurological examination were unremarkable. MRI of the brain showed an avidly homogeneous enhancing multilobulated mass centered at the right petroclival region measuring $3.6 \times 2.9 \times 4.4 \mathrm{~cm}$ (anteroposterior, transverse, and craniocaudal dimensions; Fig. 1A). Inferiorly, the mass extended into the right hypoglossal canal, invading the jugular foramen (Fig. 1B); superiorly, it extended to the right supraclinoid internal carotid artery (ICA); and posteromedially, it extended into the right prepontine cistern, effacing the right anterolateral aspect of the pons with invasion of the right cavernous sinus and right Meckel's cave (Fig. 1B and C).

Given the lesion's close relation to the ICA, cerebral angiography was performed to determine the patency of the vasculature. Cerebral angiography showed flattening and anteromedial displacement of the petrous segment of the right ICA (Fig. 2A). The right internal jugular vein was occluded prior to entering the jugular foramen (Fig. 2C). A head CT scan was obtained to establish the relationship of the chondrosarcoma with the clivus and petrous portion of the temporal bone. In addition, a CT angiogram was obtained to define the surrounding vasculature (Figs. 2B and $3)$. To access the lesion, various endoscope-assisted approaches were considered, including the extended transnasal-transsphenoidal, ipsilateral transnasal-transpterygoid, and direct midline transclival approaches. In this case, the tumor was displacing the vertical petrous segment of the ICA anteromedially and positioning it in the middle of the aforementioned trajectories, thereby hindering a safe corridor for tumor resection (Fig. 3B). Therefore, we chose an endoscope-assisted, contralateral (left-sided) transmaxillary approach to the right lateral midclivus, which provided a direct corridor to the lesion, minimizing risk of injury to the ICA.

\section{Technical Note}

After administration of general anesthesia by the neu- 


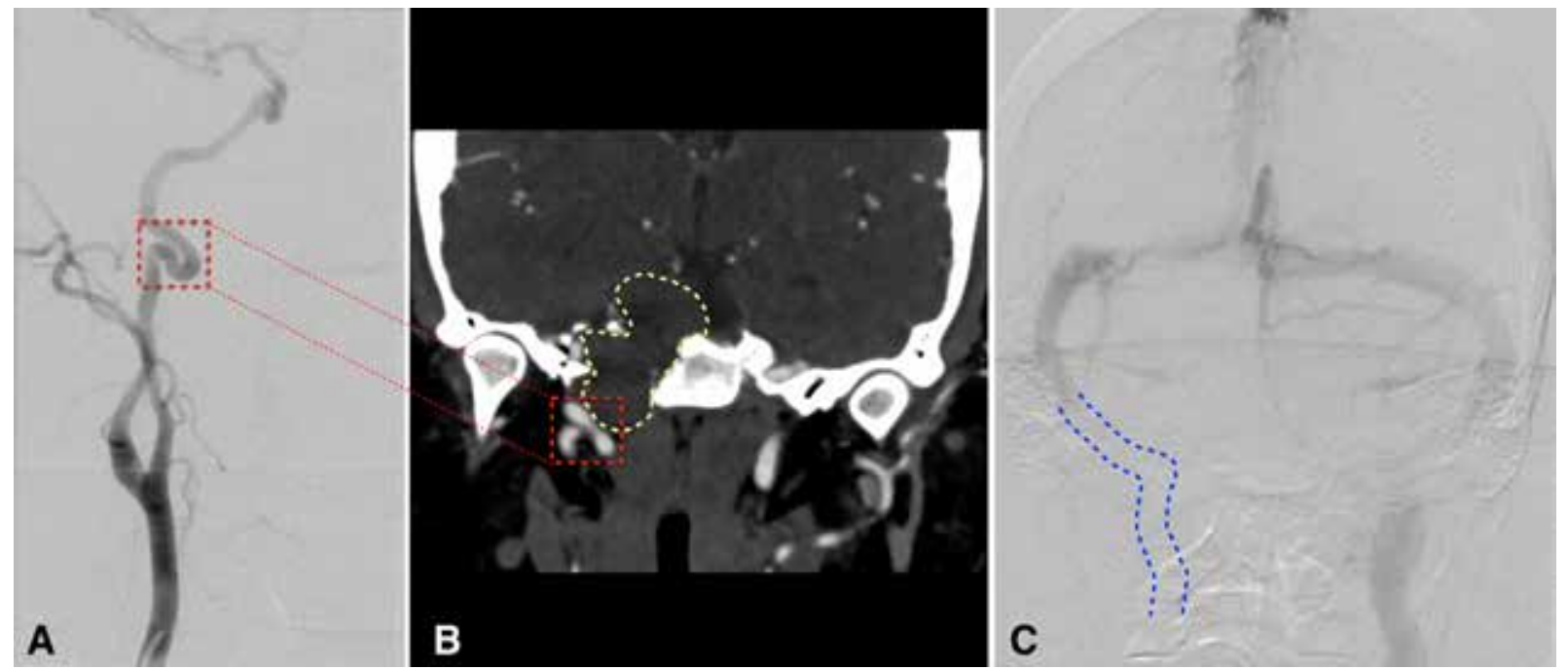

FIG. 2. A: Cerebral angiogram (oblique view, right common carotid artery injection). The red square shows anteromedial displacement and flattening of the petrous segment of the right ICA. B: CT angiogram showing distortion of the anatomical location of the petrous segment of the ICA (red square) by the tumor (yellow). C: Occlusion of the right internal jugular vein (blue) right above the jugular foramen. Figure is available in color online only.

roanesthesiology team, neurophysiological monitoring, including transcranial motor evoked potentials (MEPs), somatosensory-evoked, brainstem auditory evoked responses with monitoring of CNs IX-XII, free-run electromyography was performed, and neuromuscular junction electrodes were placed, with proper recording ensured. The patient was positioned supine, and her head was immobilized in a 3-pin Mayfield head holder. The head was angled $20^{\circ}$ above the chest and rotated $30^{\circ}$ to the right. The navigation system was registered, and its accuracy was tested. The patient's face was prepped and draped in the usual sterile fashion. The left sublabial area was exposed and infiltrated with lidocaine with epinephrine. A gingival-buccal sulcus incision was made, extending from the left canine to the left second molar. Through this incision, the anterior wall of the left maxillary sinus was exposed from the dental alveolus inferiorly to the infraorbital nerve superiorly (Fig. 4A). A left maxillary osteoplastic bone flap was planned on the anterior wall of the maxillary sinus and removed with the aid of ultrasonic bone dissector (Fig. 4B). A rigid 4-mm endoscope was inserted through the anterior maxillary bone window, and the left maxillary sinus was inspected (Fig. 5A). Using the surgical navigation probe, a direct trajectory to the right clival lesion was mapped out.

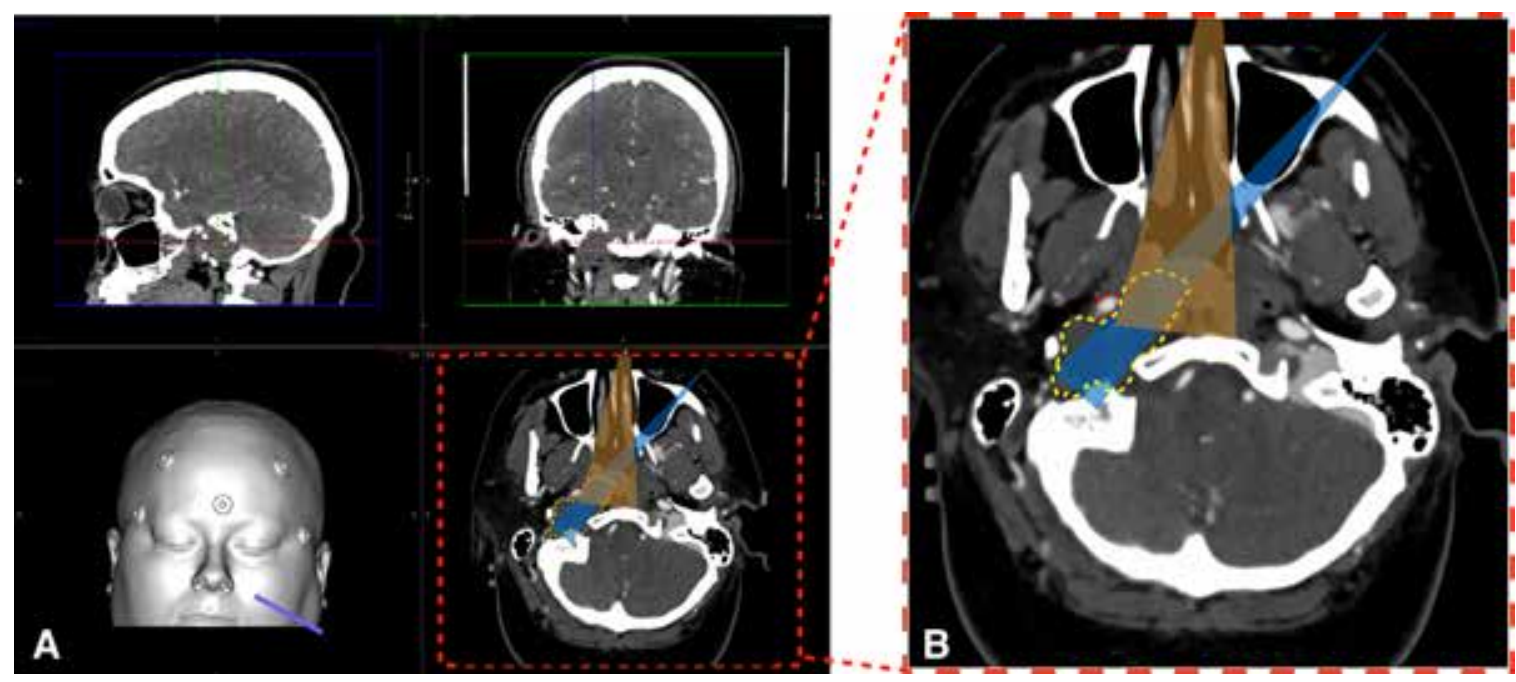

FIG. 3. A: Head CT angiograms showing the proposed contralateral trajectory to approach the right aspect of the clivus and right hypoglossal canal through a left sublabial incision. B: Axial CT angiogram comparing the trajectories and angles from the endoscopic endonasal approach (EEA) (orange) and endoscope-assisted contralateral transmaxillary approach (ECTA; blue). The EEA (orange) provides a good angle of visualization to the medial aspect of the clivus but is limited laterally by the anteriorly displaced carotid artery (red circle). ECTA (blue) provides a proper angle of approach to the medial and lateral regions of the clivus, maintaining the carotid artery at the periphery of the surgical corridor. Figure is available in color online only. 


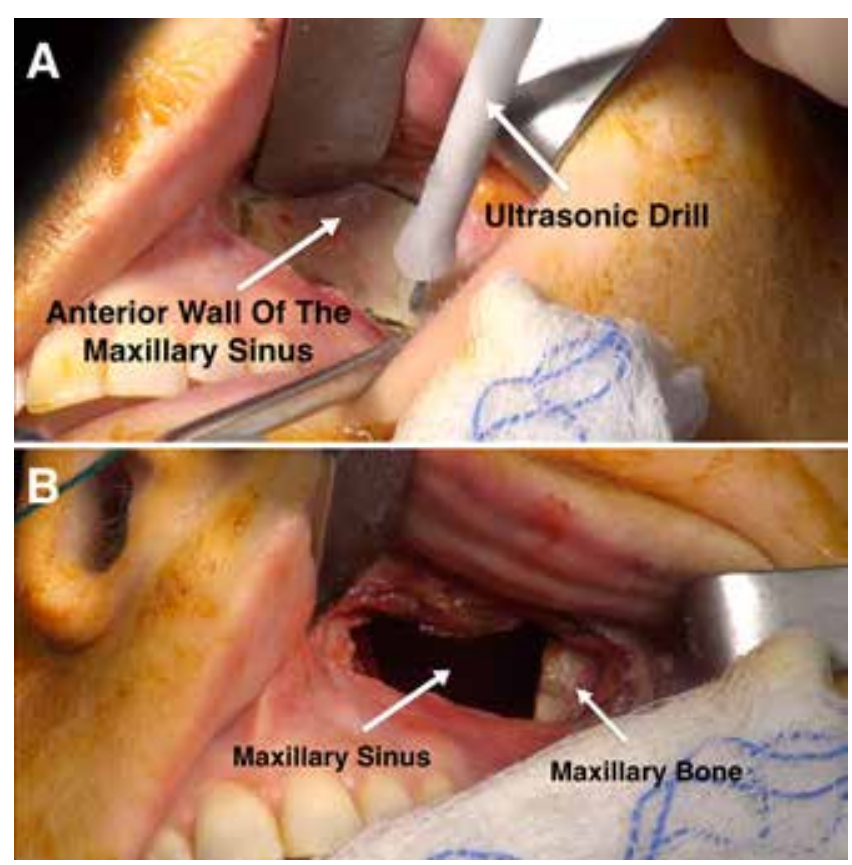

FIG. 4. A: After a sublabial incision, the anterior maxillary wall is exposed, and an anterior maxillectomy is performed using the ultrasonic drill. B: Once the anterior maxillectomy is completed, the maxillary sinus can be accessed using the endoscope. Figure is available in color online only.
The desired access corridor traversed the medial maxillary wall, posterior turbinate, left posterior nasal cavity, posterior nasal septum, and right nasopharynx. To gain access into the left nasal cavity and nasopharynx, a medial maxillectomy was completed by removing the posterior fontanelle. The posterior third of the left inferior turbinate was resected, followed by a posterior septectomy to expose the nasopharynx and clivus (Fig. 5B). The nasopharyngeal mucosa, parapharyngeal muscles, and the fascia over the paraspinal area were carefully dissected off to expose the clival bone (Fig. 5C). Using an ultrasonic bone dissector, the middle clivus was carefully opened with extension into the sphenoid sinus (Fig. 5D and E). The clival dissection was extended from superomedial to inferolateral to expose the right lower clivus and the right hypoglossal canal.

The neuronavigation system was used to map out the boundaries of the tumor in relation to the vascular structures and to direct the extent of bone removal. MicroDoppler ultrasound was utilized to define the position and the course of the vascular structures, identifying the ICA lateral and anterior to the dissection plane. Beginning from the core of the lesion, tumor removal was carefully carried out under $0^{\circ}$ rigid endoscopic visualization. The tumor was removed using a combination of ultrasonic dissection, pituitary forceps, curettes, and suction. Resection was carried out along the mesial and rostral aspect of the lesion, which allowed resolution of the mass effect on the anterolateral pons as well as the medial right temporal lobe. Ring curettes were instrumental in resecting tumor that was hidden behind the petrous apex (Fig. 5F). Once maximal tumor resection was achieved safely, the
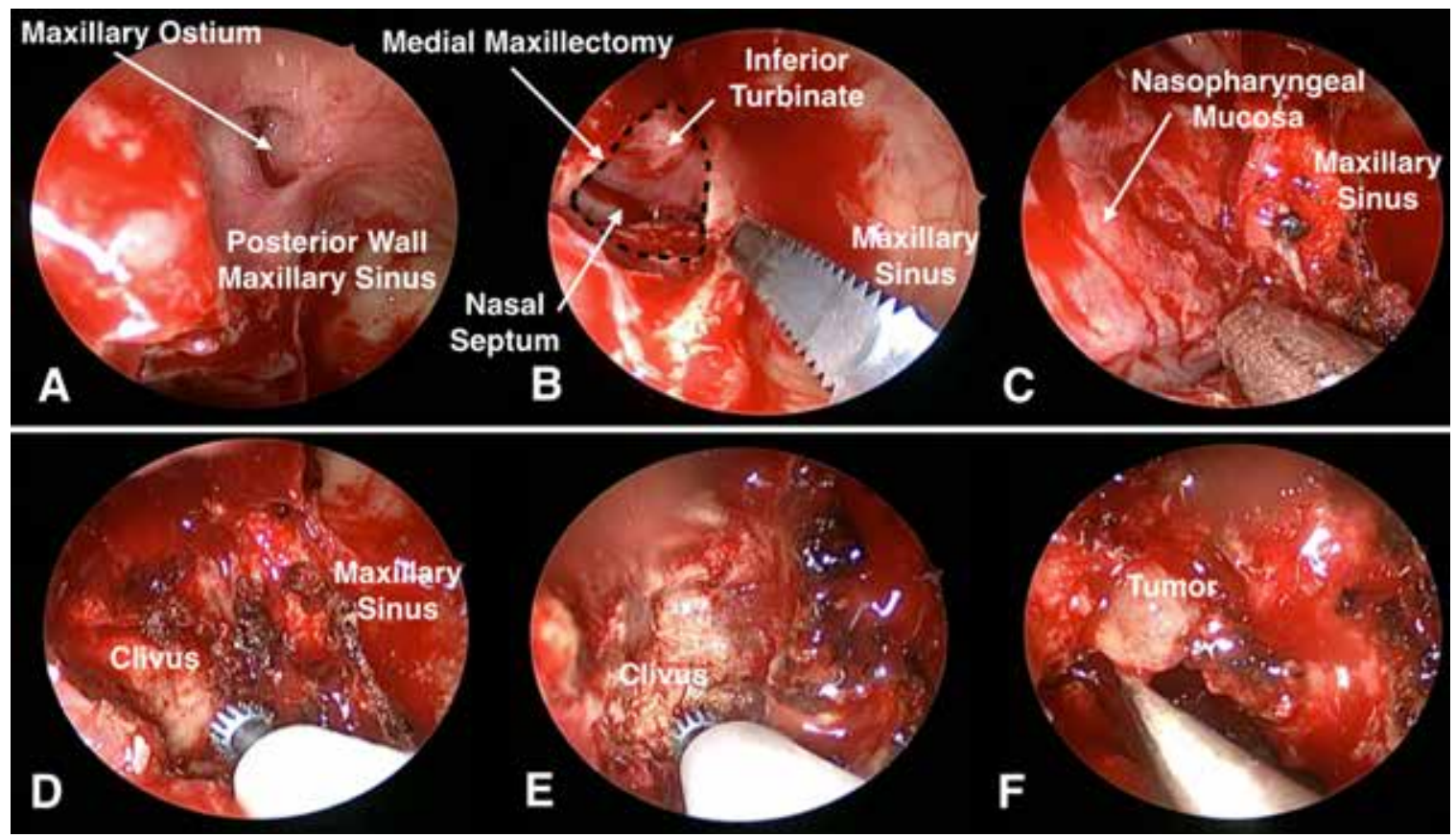

FIG. 5. ECTA to the clivus. A: Initial inspection inside the left maxillary sinus after the anterior maxillectomy. B: The middle wall of the maxillary sinus has been opened to access the posterior nasal fossa and pharyngeal space. C: Nasopharyngeal mucosa covering the clivus. D: Clivus exposure after removal of the nasopharyngeal mucosa. E: The middle and inferior clivus are drilled for tumor removal. F: The tumor was removed, and the final pathology was confirmed to be a chondrosarcoma. Figure is available in color online only. 

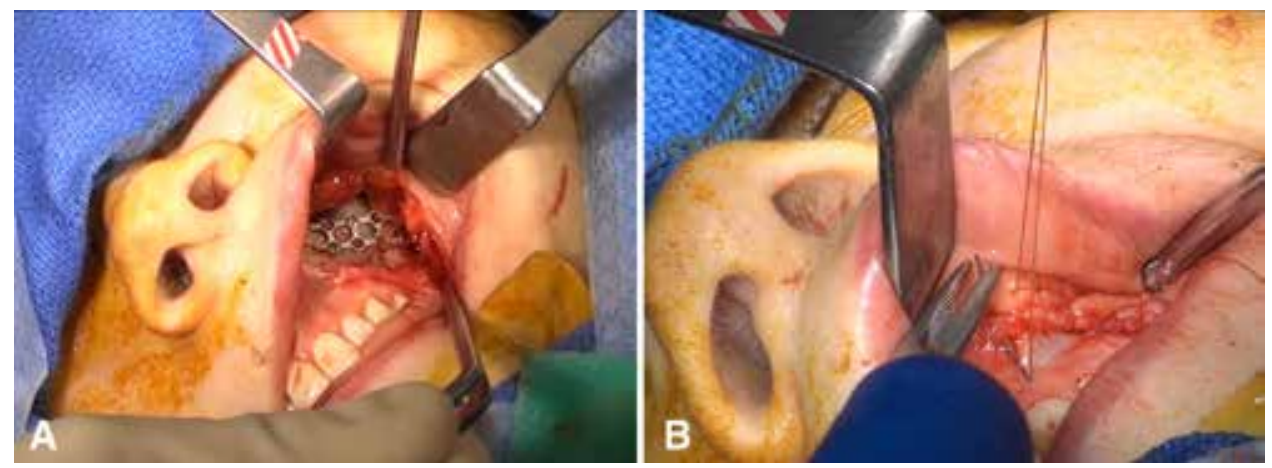

FIG. 6. A: Anterior maxillary bone replacement with titanium plate fixation. B: Closure of sublabial mucosa with absorbable suture. Figure is available in color online only.

surgical cavity was irrigated, and hemostasis was ensured (Video 1).

\section{VIDEO 1. Endoscope-assisted contralateral transmaxillary} approach to the clivus and the hypoglossal canal surgical procedure. Copyright Alfredo Quiñones-Hinojosa. Published with permission. Click here to view.

The surgical cavity was inspected to confirm that there was no CSF leak. The surgical cavity was covered with fibrin glue and Gelfoam. The previously reflected posterior nasoseptal mucosa was repositioned, and the left maxillary sinus was irrigated out. The anterior wall of the maxillary sinus was reconstructed with the osteoplastic bone flap and titanium fixation plates. The left sublabial incision was closed with absorbable sutures (Fig. 6A and B). The patient tolerated the procedure well without any complications and was transferred to the neurosurgical intensive care unit for monitoring. The patient recovered well without any new neurological deficits. Postoperative MRI showed a near-total tumor resection with a narrow rim of residual tumor (Fig. 1D-F). The patient underwent postoperative high-dose fractionated proton-beam radiation therapy at $70 \mathrm{~Gy}$, given in 38 fractions, for the residual.

\section{Pathology}

The final diagnosis based on pathology findings was grade III chondrosarcoma. The pathology slides showed highly cellular hyperchromatic pleomorphic nuclei in a myxoid background. The classic spindle growth pattern for grade III chondrosarcoma was also observed. Immunohistochemistry results were negative for cytokeratin, EMA, and GFAP, while S100 protein was positive, confirming the diagnosis of chondrosarcoma.

\section{Discussion}

Chondrosarcomas located in the clival region are slowgrowing tumors that are locally aggressive and are associated with high rates of morbidity due to local invasion of neurovascular structures. The gold-standard treatment is an extensive resection that improves the survival rate and minimizes recurrence. ${ }^{7,842}$ Studies have reported recurrence rates of $44 \%$ after subtotal resection, $19 \%$ after radiotherapy, and $9 \%$ after a combination of surgery and radiotherapy. ${ }^{7,8,42}$ Depending on the consistency of the tumor and intimate association with the ICA, gross-total resection of these tumors in this location may not be feasible. Nevertheless, the goal of neurosurgeons is to maximize the extent of resection, tempered by preservation of neurovascular function. Adjuvant radiation therapy is strongly recommended in cases in which subtotal resection is achieved?

Approaches to the clivus and hypoglossal canal can be very challenging and hazardous, requiring meticulous surgical planning. The anatomy of the clivus and all of the critical neurovascular structures within and around the clivus are major obstacles when resecting tumors in this region. The endoscopic endonasal approach to the clivus and hypoglossal canal has been previously described in many accounts, and its anatomy is well reported in the literature. . $^{1,5,12,14,16,19,23,24,32,39,41,43}$ However, the anatomical description of the endoscopic transmaxillary route to the clivus and hypoglossal canal has been rarely reported, and, to our knowledge, this is the first non-cadaveric presentation of this specific approach in a patient. ${ }^{32,43}$

Tumors in this location can alter the course of the ICA, making vascular injury one of the major concerns. It is crucial to carefully delineate the course of the ICA and its relationship with the tumor when selecting and planning any surgical approach, and performing vascular imaging, such as CTA or angiography, is highly recommended. The ICA usually enters the carotid canal anterolateral to the jugular foramen. Then, the petrous portion of the ICA runs along the temporal bone and courses medially toward the petrous apex, forming the vertical and petrous segments of the ICA. This portion of the artery then passes through the foramen lacerum, giving rise to the vidian artery before the petrolingual ligament, which is a landmark for the origin of the cavernous segment of the ICA. The ICA then courses along the medial aspect of the anterior clinoid, penetrates the dura, and becomes intracranial. ${ }^{20}$

In our case, the tumor was located in the right lateral aspect of the clivus, displacing the vertical segment of the petrous ICA anteriorly and medially (Fig. 2). Standard and extended endonasal approaches to the clivus to access this lesion necessitate significant dissection and mobilization of the ICA, increasing the potential risks of devastating vascular injury. Proximal control of the carotid artery would require wide access to the ICA in the neck (Fig. 
3). If an ICA injury occurs intraoperatively, it can be managed by packing both the transmaxillar and the endonasal corridors and with emergency endovascular intervention or transformation to open surgery, broadening the maxillectomy. After careful review of the preoperative images, we planned a surgical approach through the contralateral (left) maxillary sinus, which provided a direct surgical corridor to safely access the tumor without traversing the ICA (Fig. 3B). This approach provided access to the contralateral (right) petrous apex, right petroclival fissure, right lower clivus, and the right hypoglossal canal, which would be otherwise extremely challenging and laborious to achieve through an endoscopic endonasal approach (Fig. 3B)., ${ }^{1,5}$, $12,14,16,19,23,24,32,39,41,43$ One of the relative contraindications for endonasal endoscopic approaches is when critical neurovascular structures are localized between the dissector and the targeted lesion. ${ }^{25}$ Other alternatives for tumor resection at this location are combined approaches, such as a subtemporal-infratemporal-transpetrous apex approach that will give access to the entirety of the tumor. However, this approach also requires an extensive craniotomy and drilling of the petrous apex bone through a very small corridor that risks injury to ICA and vidian artery, and CNs V, VII, and VIII, as well as the cochlear and vestibular structures. Depending on the location and the size of the tumor, these approaches may require temporal lobe retraction. ${ }^{13,15,20,37}$ Nonsurgical treatments, such as stereotactic radiosurgery, may be considered for radiosensitive lesions less than 3.0 $\mathrm{cm}$ in diameter.

We chose a contralateral (left) maxillary sinus approach, providing a straight trajectory to the tumor, with a surgical corridor posterior to the ICA (Fig. 3B). This approach requires a multidisciplinary team consisting of otorhinolaryngologists and neurosurgeons with vast expertise in endoscopic surgery for optimal results. The neuronavigation system is an excellent tool for intraoperative guidance to confirm the bone anatomy and to create an optimal surgical corridor to the tumor. The use of intraoperative Doppler ultrasonography is critical in distinguishing the ICA from surrounding tissue. At the end of the procedure, attention should be paid to performing a diligent reconstruction in order to avoid CSF leaks and to ensure adequate hemostasis to minimize postoperative complications. A sublabial incision and a tailored middle maxillary osteotomy can help facilitate a good cosmetic result and an optimal reconstruction.

\section{Conclusions}

There are few anatomical reports of the endoscopic endonasal approach to the ipsilateral infratemporal fossa, clivus, parapharyngeal space, and infratemporal fossa. To our knowledge, there have been no previous reports describing a sublabial endoscopic contralateral transmaxillary approach to tumors invading the clivus and the hypoglossal canal. This novel approach provides a direct surgical corridor to safely access lesions located in the lateral aspects of the clivus while avoiding the need for manipulating the ICA. This approach may be considered in cases in which lesions are located on the lateral aspect of the clivus with medialized vasculature.

\section{References}

1. Abuzayed B, Tanriover N, Gazioglu N, Cetin G, Akar Z: Extended endoscopic endonasal approach to the pterygopalatine fossa: anatomic study. J Neurosurg Sci 53:37-44, 2009

2. Ammirati M, Samii M: Presigmoid sinus approach to petroclival meningiomas. Skull Base Surg 2:124-128, 1992

3. Bahr AL, Gayler BW: Cranial chondrosarcomas. Report of four cases and review of the literature. Radiology 124:151156,1977

4. Balasingam V, Anderson GJ, Gross ND, Cheng CM, Noguchi A, Dogan A, et al: Anatomical analysis of transoral surgical approaches to the clivus. J Neurosurg 105:301-308, 2006

5. Battaglia P, Turri-Zanoni M, Dallan I, Gallo S, Sica E, Padoan G, et al: Endoscopic endonasal transpterygoid transmaxillary approach to the infratemporal and upper parapharyngeal tumors. Otolaryngol Head Neck Surg 150:696-702, 2014

6. Benet A, Prevedello DM, Carrau RL, Rincon-Torroella J, Fernandez-Miranda JC, Prats-Galino A, et al: Comparative analysis of the transcranial "far lateral" and endoscopic endonasal "far medial" approaches: surgical anatomy and clinical illustration. World Neurosurg 81:385-396, 2014

7. Bloch OG, Jian BJ, Yang I, Han SJ, Aranda D, Ahn BJ, et al: Cranial chondrosarcoma and recurrence. Skull Base 20:149156, 2010

8. Crockard A: Chordomas and chondrosarcomas of the cranial base: results and follow-up of 60 patients. Neurosurgery 38:420, 1996 (Letter)

9. Crockard HA, Sen CN: The transoral approach for the management of intradural lesions at the craniovertebral junction: review of 7 cases. Neurosurgery 28:88-98, 1991

10. Cybulski GR, Russell EJ, D'Angelo CM, Bailey OT: Falcine chondrosarcoma: case report and literature review. Neurosurgery 16:412-415, 1985

11. Di Lorenzo N: Transoral approach to extradural lesions of the lower clivus and upper cervical spine: an experience of 19 cases. Neurosurgery 24:37-42, 1989

12. El-Sayed I, Pletcher S, Russell M, McDermott M, Parsa A: Endoscopic anterior maxillotomy: infratemporal fossa via transnasal approach. Laryngoscope 121:694-698, 2011

13. Fisch U, Fagan P, Valavanis A: The infratemporal fossa approach for the lateral skull base. Otolaryngol Clin North Am 17:513-552, 1984

14. Freeman JL, Sampath R, Quattlebaum SC, Casey MA, Folzenlogen ZA, Ramakrishnan VR, et al: Expanding the endoscopic transpterygoid corridor to the petroclival region: anatomical study and volumetric comparative analysis. J Neurosurg [epub ahead of print July 21, 2017; DOI: 10.3171/2017.1.JNS161788]

15. Fukushima T, Day JD, Hirahara K: Extradural total petrous apex resection with trigeminal translocation for improved exposure of the posterior cavernous sinus and petroclival region. Skull Base Surg 6:95-103, 1996

16. Gagliardi F, Donofrio CA, Spina A, Bailo M, Gragnaniello C, Gallotti AL, et al: Endoscope-assisted transmaxillosphenoidal approach to the sellar and parasellar regions: an anatomic study. World Neurosurg 95:246-252, 2016

17. Gerszten PC, Pollack IF, Hamilton RL: Primary parafalcine chondrosarcoma in a child. Acta Neuropathol 95:111-114, 1998

18. Goel A: Extended lateral subtemporal approach for petroclival meningiomas: report of experience with 24 cases. Br J Neurosurg 13:270-275, 1999

19. Gu Y, Yu Y, Zhang X, Hu F, Wang X, Xu W, et al: Endoscopic endonasal transmaxillary transpterygoid approach to Meckel cave: anatomical study and preliminary clinical results. J Neurol Surg A Cent Eur Neurosurg 76:205-210, 2015

20. Hadley KS, Shelton C: Infratemporal fossa approach to the hypoglossal canal: practical landmarks for elusive anatomy. Laryngoscope 114:1648-1651, 2004 
21. Harsh GR IV, Wilson CB: Central nervous system mesenchymal chondrosarcoma. Case report. J Neurosurg 61:375-381, 1984

22. Hassounah M, Al-Mefty O, Akhtar M, Jinkins JR, Fox JL: Primary cranial and intracranial chondrosarcoma. A survey. Acta Neurochir (Wien) 78:123-132, 1985

23. Hosseini SM, McLaughlin N, Carrau RL, Otto B, Prevedello DM, Solares CA, et al: Endoscopic transpterygoid nasopharyngectomy: correlation of surgical anatomy with multiplanar CT. Head Neck 35:704-714, 2013

24. Kantola VE, McGarry GW, Rea PM: Endonasal, transmaxillary, transpterygoid approach to the foramen ovale: radioanatomical study of surgical feasibility. J Laryngol Otol 127:1093-1102, 2013

25. Kassam AB, Gardner P, Snyderman C, Mintz A, Carrau R: Expanded endonasal approach: fully endoscopic, completely transnasal approach to the middle third of the clivus, petrous bone, middle cranial fossa, and infratemporal fossa. Neurosurg Focus 19(1):E6, 2005

26. Labram EK, Pobereskin LH, Siraj MU: Intracranial chondrosarcoma. Acta Neurochir (Wien) 139:156-157, 1997

27. Lau DP, Wharton SB, Antoun NM, Bottrill ID, Moffat DA: Chondrosarcoma of the petrous apex. Dilemmas in diagnosis and treatment. J Laryngol Otol 111:368-371, 1997

28. Laws ER Jr: Transsphenoidal surgery for tumors of the clivus. Otolaryngol Head Neck Surg 92:100-101, 1984

29. Maira G, Pallini R, Anile C, Fernandez E, Salvinelli F, La Rocca LM, et al: Surgical treatment of clival chordomas: the transsphenoidal approach revisited. J Neurosurg 85:784792, 1996

30. Miller CG, van Loveren HR, Keller JT, Pensak M, el-Kalliny M, Tew JM Jr: Transpetrosal approach: surgical anatomy and technique. Neurosurgery 33:461-469, 1993

31. Moussazadeh N, Kulwin C, Anand VK, Ting JY, Gamss C, Iorgulescu JB, et al: Endoscopic endonasal resection of skull base chondrosarcomas: technique and early results. J Neurosurg 122:735-742, 2015

32. Patel CR, Wang EW, Fernandez-Miranda JC, Gardner PA, Snyderman CH: Contralateral transmaxillary corridor: an augmented endoscopic approach to the petrous apex. $\mathbf{J}$ Neurosurg [epub ahead of print October 20, 2017; DOI: 10.3171/2017.4.JNS162483]

33. Roberti F, Sekhar LN, Jones RV, Wright DC: Intradural cranial chordoma: a rare presentation of an uncommon tumor. Surgical experience and review of the literature. J Neurosurg 106:270-274, 2007

34. Sala F, Talacchi A, Beltramello A, Iuzzolino P, Bricolo A: Intracranial myxoid chondrosarcoma with early intradural growth. J Neurosurg Sci 42:159-163, 1998

35. Samii M, Tatagiba M, Carvalho GA: Retrosigmoid intradural suprameatal approach to Meckel's cave and the middle fossa: surgical technique and outcome. J Neurosurg 92:235-241, 2000

36. Scheithauer BW, Rubinstein LJ: Meningeal mesenchymal chondrosarcoma: report of 8 cases with review of the literature. Cancer 42:2744-2752, 1978

37. Sennaroglu L, Slattery WH III: Petrous anatomy for middle fossa approach. Laryngoscope 113:332-342, 2003

38. Shekar L, Chandranath S, Snyderman C, Janecka I: Anterior, anterolateral, and lateral approaches to extradural petroclival tumors, in Sekhar LN, Janecka IP (eds): Surgery of Cranial Base Tumors. New York: Raven Press, 1993, pp 157-224

39. Taniguchi M, Kohmura E: Endoscopic transnasal transmaxillary transpterygoid approach to the parapharyngeal space: an anatomic study. Minim Invasive Neurosurg 53:255-260, 2010

40. Taylor CI, Kurbanov A, Zimmer LA, Keller JT, Theodosopoulos PV: Comparing operative exposures of the le fort I osteotomy and the expanded endoscopic endonasal approach to the clivus. J Neurol Surg B Skull Base 76:29-34, 2015

41. Upadhyay S, Dolci RL, Buohliqah L, Fiore ME, Ditzel Filho LF, Prevedello DM, et al: Effect of incremental endoscopic maxillectomy on surgical exposure of the pterygopalatine and infratemporal fossae. J Neurol Surg B Skull Base 77:66-74, 2016

42. Van Gompel JJ, Janus JR: Chordoma and chondrosarcoma. Otolaryngol Clin North Am 48:501-514, 2015

43. Wilson DA, Williamson RW, Preul MC, Little AS: Comparative analysis of surgical freedom and angle of attack of two minimal-access endoscopic transmaxillary approaches to the anterolateral skull base. World Neurosurg 82:e487-e493, 2014

\section{Disclosures}

The authors report no conflict of interest concerning the materials or methods used in this study or the findings specified in this paper.

\section{Author Contributions}

Conception and design: Quiñones-Hinojosa, Boahene. Acquisition of data: all authors. Analysis and interpretation of data: all authors. Drafting the article: all authors. Critically revising the article: all authors. Reviewed submitted version of manuscript: all authors. Approved the final version of the manuscript on behalf of all authors: Quiñones-Hinojosa. Administrative/technical/material support: all authors. Study supervision: all authors.

\section{Supplemental Information \\ Videos \\ Video 1. https://vimeo.com/257485384.}

\section{Correspondence}

Alfredo Quiñones-Hinojosa: Mayo Clinic, Jacksonville, FL. quinones-hinojosa.alfredo@mayo.edu. 